\title{
Molecular Evidence of Hepatozoon felis Infection in Wild Captured Royal Bengal Tiger Cub (Panthera tigris tigris)
}

S.M. Kolangath ${ }^{1}$, S.V. Upadhye ${ }^{1}$, V.M. Dhoot ${ }^{1}$, M.D. Pawshe ${ }^{1}$, A.S. Shalini ${ }^{1}$, P.A. Tembhurne ${ }^{2}$, S.W. Kolte ${ }^{2}$

10.18805/IJAR.B-4674

\begin{abstract}
Background: Tigers are protected under schedule I of the Wildlife Protection Act, 1972. The current report highlights the detection of Hepatoozoon felis in a tiger cub. The infection is transmitted by ingestion of infected tick, infected prey and carrion. It is subclinical in adults; however, the cubs and immunocompromised adults may show clinical symptoms. Concurrent infection with bacterial or viral infections may be fatal to the infected animal.

Methods: Hepatozoonosis was detected by blood smear examination using Giemsa staining. A PCR targeting the $18 \mathrm{~S}$ ribosomal RNA was used to confirm the infection. The amplicon was purified and sequenced using a sanger sequencer. The 18S ribosomal RNA fragment sequence was compared to the available sequences in NCBI database using the nucleotide BLAST Tool. Neighbour joining phylogenetic trees using the bootstrap method were constructed using MEGA $X$ software.

Result: The presence of an intermediate gamont stage in neutrophils was seen under high resolution. The 660 bp amplicon was purified, sequenced and analysed for identity using the nucleotide BLAST tool of NCBI. The sequence was found to be $99.32 \%$, similar to Hepatozoon felis. The phylogenetic analysis by neighbour joining phylogenetic tree using the bootstrap method indicated similarity with other reported sequences of $H$. felis isolated from Asian Lions. The sequence, however, was very dissimilar to the previously reported $\mathrm{H}$. felis isolated from Royal Bengal Tiger. Considering the potential threat Hepatozoonosis can have in the wild, the prevalence must be estimated in prey base, sympatric cat species and arthropod vectors.

Key words: Conservation efforts, Hepatozoon canis, Hepatozoon felis, Leucocytozoon, Rhipicephalus, Royal Bengal Tiger, Wildlife.
\end{abstract}

\section{INTRODUCTION}

India is one of the seventeen mega diversities around the world. The rich flora and fauna of the country have aesthetic and cultural value. India is home to many endangered wild animals, including the Royal Bengal Tiger (Panthera tigris tigris). Royal Bengal Tigers were once distributed all over the country; today, 2967 tigers are the last survivors of the species. They have been a flagship species, keystone species and umbrella species for conservation efforts in the country. Central India is home to over 850 tigers and is an essential corridor for gene flow. India is a tropical country; the hot and humid conditions are conducive to the growth and propagation of the ticks. Ticks transmit an array of haemoprotozoal diseases in dogs and cats in the Indian subcontinent. In the wild, ticks play a significant role in transmitting a variety of haemoprotozoal diseases across species. Hepatozoonosis is one such leucocytozoon infection that is transmitted by the ticks of Rhipicephalus and Amblyomma species. The infection is transmitted by ingestion of infected tick and vertical transmission Gardiner and Poynton (2006). Hepatozoonosis has been documented widely in domestic dogs Lauzi et al. (2016), de Sousa et al. (2017) and cats Pereira et al. (2019), Diaz-Reganon et al. (2017); Andre et al. (2015); Braga et al. (2016), de Bartoli et al. (2011); Kegler et al. (2018); Kubo et al. (2010). However, the reporting in the wild is limited to canids East et al. (2008); Giannitti et al. (2012), ursids Pawar et al. (2011), felids Pawar et al. (2012); Furtado et al. (2017); Hodzic et al.
${ }^{1}$ Wildlife Research and Training Centre, Maharashtra Animal and Fishery Sciences University, Nagpur-440 006, Maharashtra, India. ${ }^{2}$ Nagpur Veterinary College, Maharashtra Animal and Fishery Sciences University, Nagpur-440 006, Maharashtra, India.

Corresponding Author: S.M. Kolangath, Department of Animal Biotechnology, Wildlife Research and Training Centre, Maharashtra Animal and Fishery Sciences University, Nagpur-440 006, Maharashtra, India. Email: brosujit@gmail.com

How to cite this article: Kolangath, S.M., Upadhye, S.V., Dhoot, V.M., Pawshe, M.D., Shalini, A.S., Tembhurne, P.A. and Kolte, S.W. (2022). Molecular Evidence of Hepatozoon felis Infection in Wild Captured Royal Bengal Tiger Cub (Panthera tigris tigris). Indian Journal of Animal Research. DOI: 10.18805/IJAR.B-4674.

Submitted: 12-06-2021 Accepted: 15-01-2022 Online: 08-03-2022 (2018); Tateno et al. (2015), rodents Kamani et al. (2018), reptiles Ujvari et al. (2004). Clinically, the diagnosis of Hepatozoonosis is carried out by conventional blood smear examination; however, as indicated by Otranto et al., (2011) low levels of the parasite in circulation and distinct life cycle involving specific sites of merogony and cyst formation may limit the utility of blood smear examination. Hence, a sensitive molecular method is needed in the early and subclinical diagnosis of Hepatozoonosis. Molecular techniques that detect the presence of nucleic acid have been widely used to detect blood protozoans in domestic and wild animals. The current study detected Hepatozoonosis 
in wild Royal Bengal Tiger (Panthera tigris tigris) based on blood smear examination and nucleic acid amplification test using Polymerase Chain Reaction. Sequencing and phylogenetic analysis can provide an insightful understanding of the epidemiological drivers of Hepatozonosis in large wild felids. A nine-month-old male Royal Bengal Tiger cub was found abandoned at Tadoba Tiger Reserve (TTR). The tiger cub was weak, anaemic, tick-infested and was rescued, treated rationally at Tadoba Tiger Reserve. It was sent for further care to Gorewada Wild Animal Rescue Centre, Nagpur. During the routine diagnosis, the blood smear examination revealed the infection with Hepatozoon sp. Efforts were made to identify the species of hemoprotozoan by using polymerase chain reaction and sequencing.

\section{MATERIALS AND METHODS}

The research work described hereunder was performed at Wildlife Research and Training Centre, Gorewada, Nagpur from 21.03.2020 to 13.09.2020.

\section{Blood collection}

The tiger was restrained in a squeeze cage. The blood sample was collected from the lateral coccygeal vein in the potassium-EDTA vial. Blood smears were made and allowed to dry at room temperature. The smears were stained with Leishman stain and Giemsa stain and examined under $100 \mathrm{X}$ under oil immersion.

\section{DNA isolation}

$100 \mu \mathrm{l}$ of blood was used to isolate DNA using DNeasy® Blood and Tissue Kit (Mfg. Qiagen Inc, MD, USA) as per the manufacturer's instruction. The final step was modified wherein the DNA was eluted in $35 \mu$ of warm Nuclease Free Water (NFW) (Mfg. Invitrogen).

\section{Polymerase chain reaction}

Primer pairs HepF (5'-ATA CAT GAG CAA AAT CTC AAC-3') and HepR (5'-CTT ATT ATT CCA TGC TGC AG-3') as suggested by Inokuma et al. (2002) were utilised for targeting the $18 \mathrm{~S}$ ribosomal RNA gene of Hepatozoon sp. $25 \mu \mathrm{l}$ reactions were set using Go Taq Green 2X Master Mix (Mfg. Promega Corp. Madison, USA), forward and reverse primers $50 \mathrm{pM}$ each and one $\mu \mathrm{g}$ of the template. The conditions for PCR were $94^{\circ} \mathrm{C}$ for $30 \mathrm{sec}$; 40 cycles of $94^{\circ} \mathrm{C}$ for $30 \mathrm{sec}$, $57^{\circ} \mathrm{C}$ for $30 \mathrm{sec}, 72^{\circ} \mathrm{C}$ for $60 \mathrm{sec}$; followed by final extension of $72^{\circ} \mathrm{C}$ for 10 minutes. For intrinsic species control, tigerspecific primers $\mathrm{Pta}-\mathrm{CbF}$ and $\mathrm{Pta}-\mathrm{CbR}$ targeting the Cytochrome $b$ gene were used. The primers produced an amplification of 270 bp Sugimoto et al. (2006).

\section{Agarose gel electrophoresis}

The products amplified post polymerase chain reaction was analysed on $1 \%$ agarose gel with ethidium bromide. The electrophoresis was carried out at $90 \mathrm{~V}$ for 60 minutes. $1 \mathrm{~Kb}$ DNA ladder (Cat. No. SM0323, Invitrogen) was used as a reference for molecular weight. The gel was viewed under
UV light in a gel documentation system (Mfg. Syngene, MD, USA).

\section{Polymerase Chain Reaction product purification}

As per the manufacturer's directions, the PCR products were purified using Qiaquick ${ }^{\circledR}$ PCR Purification Kit (Mfg. Qiagen Inc, MD USA).

\section{Amplicon sequencing}

The PCR purified product was sequenced using HepF and HepR primer pair. The ABI 3130 automated DNA sequencer (Mfg. Applied Biosystems, CA, USA). The amplicon was sequenced using the forward and reverse primers for accuracy. The raw sequence was analysed using MEGA $X$ (Version 10.1.8) contig sequence was created by manual editing using Bioedit software.

\section{BLAST analysis}

The sequence obtained was submitted to the National Centre for Biotechnology Information (NCBI) (https:// www.ncbi.nlm.nih.gov) using the nucleotide Blast tool for calculating the identity of the sequence with reported sequences. Using the Bankit sequence submission tool, the sequence was submitted to NCBI nucleotide database.

\section{Phylogenetic analysis}

Using Mega X (Version 10.1.8) (Kumar et al., 2018), identical sequences of Hepatozoon identified in wild animals were preferentially included in the study. Neighbour joining phylogenetic trees using the bootstrap method were constructed using Mega X software to study the topologies of the phylogenetic trees. The bootstrap values (1000 replications) were analysed to ensure tree consistency. Twenty-seven sequences isolated from wild mammals were selected from the BLAST analysis and aligned for phylogenetic analysis. Plasmodium vivax (Accession No. DQ162167) was used as an outgroup to root the tree.

\section{RESULTS AND DISCUSSION}

The blood smear examination revealed gamont stages in the neutrophils (Fig 1) of the infected tiger. The PCR analysis followed by $1 \%$ agarose gel electrophoresis revealed amplification of 660 base pairs as described by Inokuma et al. (2002) (Fig 2). The amplicon was purified and sequenced; the sequence so obtained was submitted to NCBI (https:// www.ncbi.nlm.nih.gov). The sequence was granted an accession no. MT634695 by NCBI, BLAST analysis revealed the causative agent to be $H$. felis with $99.32 \%$ similarity to previously reported $H$. felis from wild and domestic animals. The sequence was identical to the sequence of Hepatozoon isolated from Indian wild cats like Asiatic Lion (HQ829439, HQ829438).

Sequences reported from wild animals were preferentially considered for the phylogenetic analysis. The neighbour joining tree could be divided into five subclades $H$. canis, $H$. felis, $H$. ursi, $H$. silvestris and $H$. americanum (Fig 3 ). The $H$. felis isolate WRTC 2020 formed a significant clade 
with other sequences of $H$. felis reported worldwide in wild felids with a bootstrap value of $93 \%$. The $H$. ursi formed a separate clade with bootstrap value of $81 \%$. $H$. silvestris and $H$. americanum formed two separate clades with bootstrap values $84 \%$ and $83 \%$ respectively. The H.canis formed a separate clade with bootstrap value of $81 \%$ and Plasmodium vivax as anoutgroup. It is worth mentioning that $H$. felis reported by Pawar et al., 2012 from Royal Bengal Tiger (Accession No. HQ829445) showed only $97.43 \%$ identity with the $18 \mathrm{~S}$ ribosomal RNA partial gene fragment under study. The findings designate considerable genetic diversity in the reported genotypes of Hepatozoon from many felids in India and abroad Rafiqi et al. (2018).

In the current study, sensitive PCR was employed to provide molecular evidence; this was further supplemented with sequencing and phylogenetic studies to provide insights on the qualitative aspect of epizootiology. The detection of $H$. felis in a wild tiger cub is perilous because tiger cubs generally wean at 24 months of age and grooming of cubs by dams is common in tigers. Transplacental transmission makes the infection more alarming as a dam brings forth three to four cubs in each queening. Moreover, Tadoba Tiger Reserve (TTR) is connected to many tiger landscapes in the northern part of the country. Tiger migrations from Tadoba to northern lying tiger landscapes have been reported by many workers Sharma et al. (2013), Joshi et al. (2013). The quantum of intra-species transmission is challenging to predict considering the thick population of the tigers and their innate migrating behaviour.

Hepatozonosis in wild animals is primarily subclinical. However, reports of death in hyenas have been reported by East et al. (2008). The clinical form of the disease has been reported in very young and immunocompromised wild animals Garret et al. (2005). Unlike other hemoprotozoan infections, the transmission of the infection is due to ingestion of infected arthropod, infected prey or carrion. Persistent viral and bacterial infection weakens the host's immunity; these immunocompromised hosts may be prone to Hepatozoonosis. Penzhorn et al. (2006) highlighted the influence of stress, habitat destruction, adverse climatic conditions and immunosuppression as important factors affecting the spread of Hepatozoonosis under wild conditions. Munson et al. (2008) highlighted the impact of climatic extremes, canine distemper and babesiosis coinfections in the death of African Lions in Serengeti, Africa. Similarly, Rafiqi et al. (2018) have cautioned regarding the splaying of mortality in endangered wildlife due to immunosuppression and co-infection with immunosuppressive pathogens. In the current study, the tiger cub was reported to be thickly infested with ticks; thus, the chance of transmission of hepatozoon infection due to ingestion of infected tick cannot be ruled out. There is no publication on the prevalence of Hepatozoonosis in the prey species of India like spotted deer (Axis axis), nilgai (Boselaphus tragocamelus), gaur (Bos gaurus), sambar (Rusa unicolor), black buck (Antilope cervicapra), four-horned antelope (Tetracerus quadricornis) etc. Wild carnivores may also act as reservoirs of the infection and propagate the infection to other wild animals Kocan et al., (2000). Thus, definite information of the host range infected with Hepatozoonosis is lacking.

Since infection in wild animals is asymptomatic, hemoprotozoon infections like Hepatozoonosis have received less consideration. The detection of Hepatozoonosis in domestic and wild animals primarily depends on blood smear examinations. When the quantum of infection is subclinical, blood smears may not provide evidence at an early stage of the infection. Thus, molecular techniques can be a handy tool to detect Hepatozoonosis under field

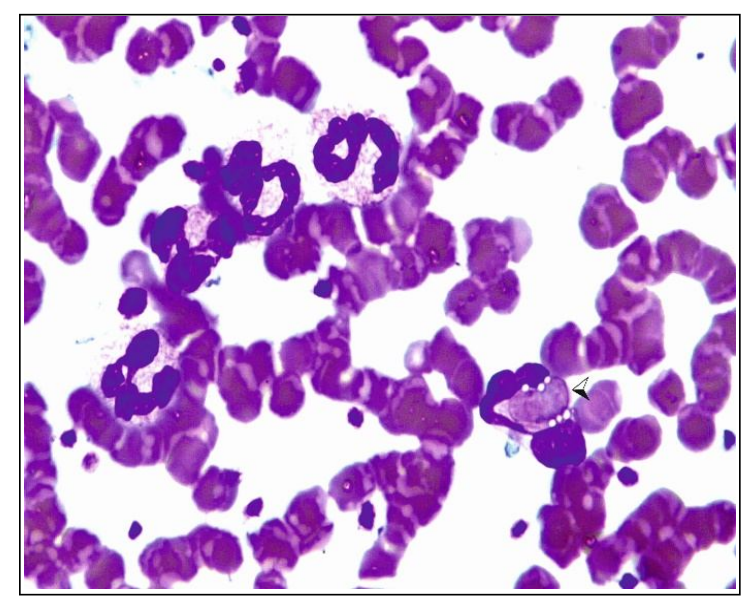

Fig 1: Gamont stage of Hepatozoon in Neutrophils (indicated by arrow) by Giemsa Staining.

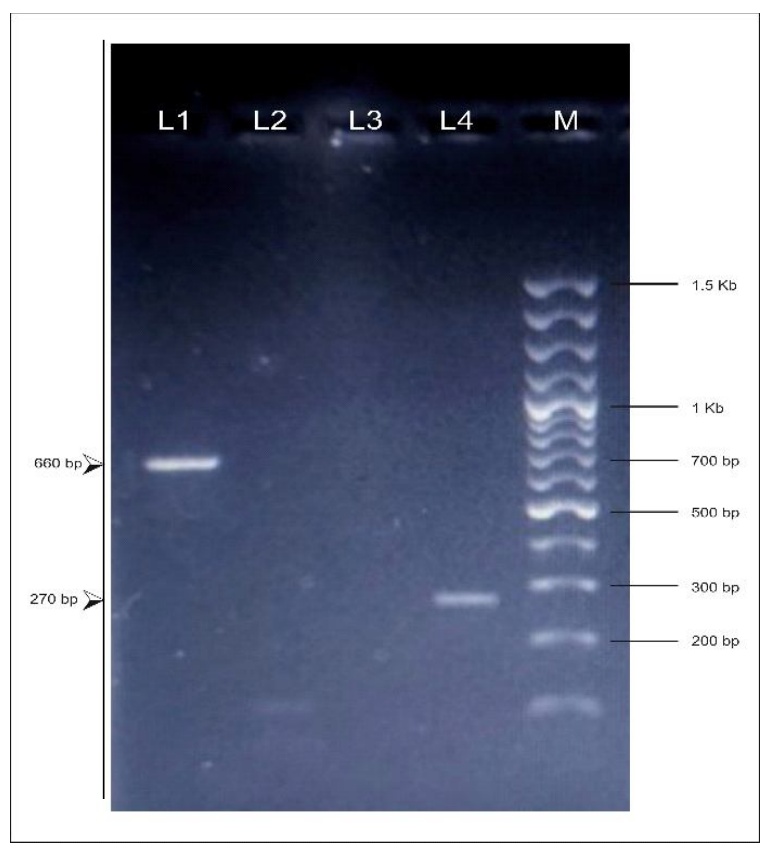

Fig 2: PCR amplification as described by Inokuma et al., 2002. Lane 1: Amplicon of $660 \mathrm{bp}$; Lane 2: Negative Sample; Lane 3: Negative Control; Lane 4: Species control (Positive, Control); Lane $\mathrm{M}$ : Ladder $1 \mathrm{~Kb}$. 


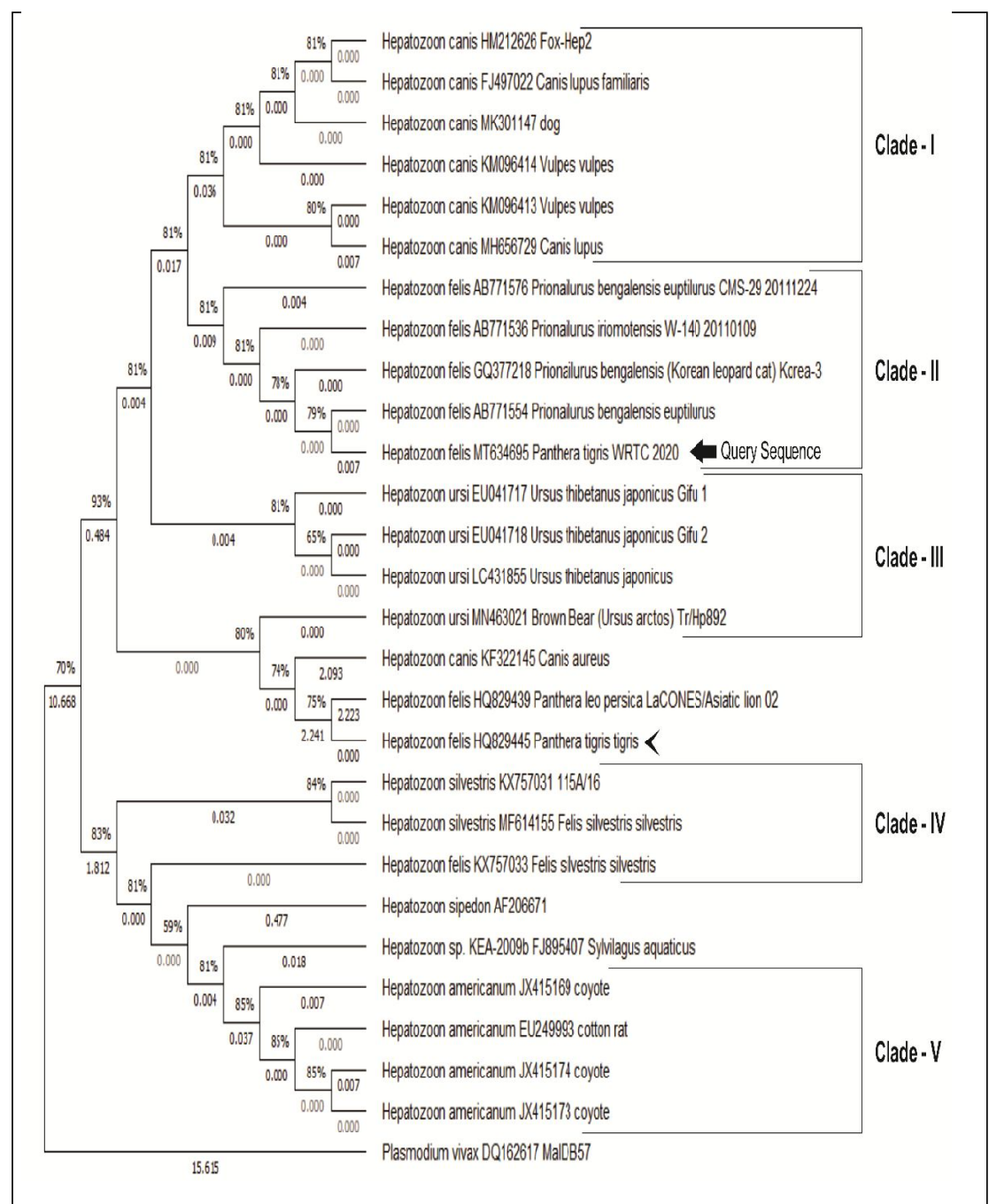

Fig 3: Phylogenetic Analysis of Sequence by Neighbour Joining Phylogenetic Tree using Bootstrap Method (1000 replications).

conditions. PCR and real-time PCR can be utilised for the detection of Hepatozoonosis in wild animals. Rhipicephalus spp. and Amblyomma spp. ticks also transmit many other hemoprotozoal infections, which are also under-studied. Anderson et al. (2013) were the first to provide evidence of Anaplasma platys and Hepatozoon canis co-infection in dogs. Very little information on co-infection in wild species is currently available; hence, the need for sensitive molecular techniques to investigate the prevalence of Hepatozoonosis in the wild is greatly felt.

\section{CONCLUSION}

Tigers play an essential role in maintaining the ecosystem and have social, cultural and aesthetic value. Hepatozonosis in Royal Bengal Tiger cubs can prove to be possibly fatal. The potential of arthropod vectors to transmit the disease to other healthy tigers cannot be ruled out as Tadoba Tiger Reserve is home to over 115 tigers. No data is available on the current prevalence of Hepatozoonosis in the landscape. It is essential to study the prevalence of Hepatozoonosis in the wild, considering the potential threat in case of a concurrent bacterial or viral epizootic in the species.

\section{ACKNOWLEDGEMENT}

The study is not a clinical trial; hence no ethical approval was required; however, permission from PCCF (Wildlife), Maharashtra State, was sought for the study and publication of scientific findings. The authors acknowledge the support received from Officials of Forest Development Cooperation of Maharashtra Ltd., Nagpur and Divisional Manager, Gorewada Project, Nagpur in conducting the study.

\section{Conflicts of interest: None.}

\section{REFERENCES}

Andersson, M., Turcitu, M. A., Stefanache, M., Tamba, P., Barbuceanu, F. and Chitimia, L. (2013). First evidence of Anaplasmaplatys and Hepatozoon canis co-infection in a dog from Romania-A case report. Ticks and TickBorne Diseases. 4(4): 317-319. 
André, M.R., Herrera, H.M., de Jesus Fernandes, S., de Sousa, K.C.M., Gonçalves, L.R., Domingos, I.H., de Macedo, G.C. and Machado, R.Z. (2015). Tick-borne agents in domesticated and stray cats from the city of Campo Grande, State of Mato Grosso do Sul, midwestern Brazil. Ticks and Tick-Borne Diseases. 6(6): 779-786.

Braga, İ.A., de Souza Ramos, D.G., Marcili,A., Melo, A.L.T., Taques, I.I.G.G., Amude, A.M., Chitarra, C.S., Nakazato, L., Dutra, V., de Campos Pacheco, R. and Aguiar, D.M. (2016). Molecular detection of tick-borne protozoan parasites in a population of domestic cats in midwestern Brazil. Ticks and Tick-Borne Diseases. 7(5): 1004-1009.

de Sousa, K.C., Fernandes, M.P., Herrera, H.M., Benevenute, J.L., Santos, F.M., Rocha, F.L., Barreto, W.T., Macedo, G.C., Campos, J.B., Martins, T.F. and de Andrade Pinto, P.C. (2017). Molecular detection of Hepatozoon spp. in domestic dogs and wild mammals in southern Pantanal, Brazil with implications in the transmission route. Veterinary Parasitology. 237: 37-46.

deBortoli, C.P., André, M.R., Maria do Socorro, C.B., Machado, R.Z. (2011). Molecular characterization of Hepatozoon $\mathrm{sp}$. in cats from São Luís Island, Maranhão, northeastern Brazil. Parasitology Research. 109(4): 1189.

Díaz-Regañón, D., Villaescusa, A., Ayllón, T., Rodríguez-Franco, F., Baneth, G., Calleja-Bueno, L., García-Sancho, M., Agulla, B., Sainz, Á. (2017). Molecular detection of Hepatozoon spp. and Cytauxzoon sp. in domestic and stray cats from Madrid, Spain. Parasites and Vectors. 10(1): 112.

East, M.L., Wibbelt, G., Lieckfeldt, D., Ludwig, A., Goller, K.,Wilhelm, K., Schares, G., Thierer, D., Hofer, H. (2008). A Hepatozoon species genetically distinct from $H$. canis infecting spotted hyenas in the Serengeti ecosystem, Tanzania. Journal of Wildlife Diseases. 44(1): 45-52.

Furtado, M.M., Metzger, B., de Almeida Jácomo, A.T., Labruna, M.B., Martins, T.F., O'Dwyer, L.H., Paduan, K.D., Porfírio, G.E., Silveira, L., Sollmann, R. and Taniwaki, S.A. (2017). Hepatozoon spp. infect free-ranging jaguars (Panthera onca) in Brazil. Journal of Parasitology. 103(3): 243-50.

Gardiner, C.H. and Poynton, S.L. (2006). An Atlas of Metazoan Parasites in Animal Tissues Armed Forces Institute of Pathology. Washington DC, USA.

Garrett, J.J., Kocan, A.A., Reichard, M.V., Panciera, R.J., Bahr, R.J. and Ewing, S.A. (2005). Experimental infection of adult and juvenile coyotes with domestic dog and wild coyote isolates of Hepatozoon americanum (Apicomplexa: Adeleorina). Journal of Wildlife Diseases. 41(3): 588-92.

Giannitti, F., Diab, S.S., Uzal, F.A., Fresneda, K., Rossi, D., TalmiFrank, D. and Baneth, G. (2012). Infection with a Hepatozoon sp. closely related to Hepatozoon felis in a wild Pampas gray fox (Lycalopex- pseudalopex-gymnocercus) co-infected with canine distemper virus. Veterinary Parasitology. 186(34): 497-502.

Hodžić, A., Mrowietz, N., Cezanne, R., Bruckschwaiger, P., Punz, S., Habler, V. E., Tomsik, V., Lazar, J., Duscher, G.G., Glawischnig, W., Fuehrer, H.P. (2018). Occurrence and diversity of arthropod-transmitted pathogens in red foxes (Vulpes vulpes) in western Austria and possible vertical (transplacental) transmission of Hepatozoon canis. Parasitology. 145(3): 335-44.
Inokuma, H., Okuda, M., Ohno, K., Shimoda, K., Onishi, T. (2002). Analysis of the 18S rRNA gene sequence of a Hepatozoon detected in two Japanese dogs. Veterinary Parasitology. 106(3): 265-71.

Joshi, A., Vaidyanathan, S., Mondol, S., Edgaonkar, A., Ramakrishnan, U. (2013). Connectivity of tiger (Panthera tigris) populations in the human-influenced forest mosaic of central India. PloS One. 8(11): 77980.

Kamani, J., Harrus, S., Nachum-Biala, Y., Gutiérrez, R., Mumcuoglu, K.Y., Baneth, G. (2018). Prevalence of Hepatozoon and Sarcocystis spp. in rodents and their ectoparasites in Nigeria. Acta Tropica. 187: 124-8.

Kegler, K., Nufer, U., Alic, A., Posthaus, H., Olias, P. and Basso, W. (2018). Fatal infection with emerging apicomplexan parasite Hepatozoon silvestris in a domestic cat. Parasites and Vectors. 11(1): 428.

Kocan, A.A., Cummings, C.A., Panciera, R.J., Mathew, J.S., Ewing, S.A. and Barker, R.W. (2000). Naturally occurring and experimentally transmitted Hepatozoon americanum in coyotes from Oklahoma. Journal of Wildlife Diseases. 36(1): 149-53.

Kubo, M., Jeong, A., Kim, S.I., Kim, Y.J., Lee, H., Kimura, J., Agatsuma, T., Sakai, H. and Yanai, T. (2010). The first report of Hepatozoon species infection in leopard cats (Prionailurus bengalensis) in Korea. Journal of Parasitology. 96(2): 437-439.

Kumar, S., Stecher, G., Li, M., Knyaz, C. and Tamura, K. (2018). MEGA X: molecular evolutionary genetics analysis across computing platforms. Molecular Biology and Evolution. 35(6): 1547-49.

Lauzi, S., Maia, J.P., Epis, S., Marcos, R., Pereira, C., Luzzago, C., Santos, M., Puente-Payo, P., Giordano, A., Pajoro, M. and Sironi, G. (2016). Molecular detection of Anaplasmaplatys, Ehrlichia canis, Hepatozoon canis and Rickettsia monacensis in dogs from Maio Island of Cape Verde archipelago. Ticks and Tick-Borne Diseases. 7(5): 964-69.

Munson, L., Terio, K.A., Kock, R., Mlengeya, T., Roelke, M.E., Dubovi. E.,Summers, B., Sinclair, A.R. and Packer, C. (2008). Climate extremes promote fatal co-infections during canine distemper epidemics in African lions. PloS One. 3(6): 2545.

Otranto, D., Dantas-Torres, F., Weigl, S., Latrofa, M.S., Stanneck, D., Decaprariis, D., Capelli, G. and Baneth, G. (2011). Diagnosis of Hepatozoon canis in young dogs by cytology and PCR. Parasites and Vectors. 4(1): 1-6.

Pawar, R.M., Poornachandar, A., Arun, A.S., Manikandan, S. and Shivaji, S. (2011). Molecular prevalence and characterization of Hepatozoon ursi infection in Indian sloth bears (Melursus ursinus). Veterinary Parasitology. 182(2-4): 329-32.

Pawar, R.M., Poornachandar, A., Srinivas, P., Rao, K.R., Lakshmikantan, U. and Shivaji, S. (2012). Molecular characterization of Hepatozoon spp. infection in endangered Indian wild felids and canids. Veterinary Parasitology. 186(3-4): 475-79.

Penzhorn, B.L., Kjemtrup, A.M., López-Rebollar, L.M. and Conrad, P.A. (2001). Babesia leo n. sp. from lions in the Kruger National Park, South Africa, and its relation to other small piroplasms. Journal of Parasitology. 87(3): 681-5. 
Pereira, C., Maia, J.P., Marcos, R., Luzzago, C., Puente-Payo, P., Dall'Ara, P., Faustino, A. and Lauzi, S. (2019). Molecular detection of Hepatozoon felis in cats from Maio Island, Republic of Cape Verde and global distribution of feline Hepatozoonosis. Parasites and Vectors. 12(1): 1-9.

Rafiqi, S.I., Kumar, S., Reena, K.K., Garg, R., Ram, H., Karikalan, M., Mahendran, K., Pawde, A.M., Sharma, A.K., Banerjee, P.S. (2018). Molecular characterization of Hepatozoon sp. and Babesia sp. isolated from endangered Asiatic Lion (Panthera leo persica). Indian Journal of Animal Science. 88: 662-666.

Sharma, S., Dutta, T., Maldonado, J.E., Wood, T.C., Panwar, H.S. and Seidensticker, J. (2013). Forest corridors maintain historical gene flow in a tiger metapopulation in the highlands of central India. Proceedings of the Royal Society B: Biological Sciences. 280(1767): 20131506.
Sugimoto, T., Nagata, J., Aramilev, V.V., Belozor, A., Higashi, S. and McCullough, D.R. (2006). Species andsex identification from faecal samples of sympatric carnivores, Amur leopard and Siberian tiger, in the Russian Far East. Conservation Genetics. 7(5): 799-802.

Tateno, M., Sunahara, A., Nakanishi, N., Izawa, M., Matsuo, T., Setoguchi, A. and Endo, Y. (2015). Molecular survey of arthropod-borne pathogens in ticks obtained from Japanese wildcats. Ticks and Tick-Borne Diseases. 6(3): 281-89.

Ujvari, B., Madsen, T. and Olsson, M. (2004). High prevalence of Hepatozoon spp. (Apicomplexa, Hepatozoidae) infection in water pythons (Liasis fuscus) from tropical Australia. Journal of Parasitology. 90(3). 670-72. 